\title{
CONDITIONS FOR REDUCING SPHERICAL THERMAL ABERRATIONS IN TRANSVERSALLY PUMPED YAG RODS
}

\author{
D. Bričkus and A.S. Dement'ev \\ Center for Physical Sciences and Technology, Savanoriu 231, LT-02300 Vilnius, Lithuania \\ E-mail: aldement@ktl.mii.lt
}

Received 7 March 2016; revised 18 April 2016; accepted 21 June 2016

\begin{abstract}
Temperature dependences of the thermal conductivity and thermo-optic coefficient are often neglected when thermal lensing in laser crystals is investigated, though their influence is very significant. In this paper, the general solution of heat transfer equation with temperature dependent thermal conductivity is found in an integral form, which is very convenient for analytical and numerical analysis. Using this solution, the possibility to eliminate spherical aberration by a proper choice of the pump parabolicity parameter is investigated in detail. The inaccuracies in the definition of optical path differences used in a few previous works for the case of temperature dependent thermo-optic coefficient are explained. It is shown that the use of a correct definition increases the value of the parabolic coefficient at which the elimination of spherical aberrations may be realized as compared with the original work of Hodgson and Weber. It is also found that nearly the same shapes of pumping are required for elimination of spherical aberrations for both radial and tangential polarization.
\end{abstract}

Keywords: solid-state laser, thermal effect, spherical aberration

PACS: 42.25.Lc, 42.55.Xi, 78.20.hb

\section{Introduction}

Thermally induced spherical aberrations in solid state lasers are one of the main issues for beam quality degradation in high average power systems [1-5]. Therefore, many studies have been made to find methods for the compensation of thermal lens (TL) aberrations and improving the beam quality [1-12]. One of the causes for spherical aberrations occurring is an inhomogeneity of the radial pump distribution. A simplified model for the dependence of thermal lensing on the transverse intensity profile of the pump beam was first developed for the temperature independent parameters of the active element (AE) [1, 8]. However, another reason for the occurrence of spherical aberrations in the $\mathrm{AE}$ is the temperature dependence of its thermal conductivity [2, 3, , , 9, 10, 12-17]. It follows from this dependence that the radial temperature distribution has higher nonparabolic terms even for homogeneous heat loading in the AE [6, 耳]. It has been noted [7] that for the temperature independent thermo-optic coefficient $\mathrm{d} n / \mathrm{d} T$ it is possible to compensate the spherical aberration induced due to the temperature dependence of its thermal conductivity by a properly shaped pumping distribution. The results of [⿰] were reproduced in the first edition of monograph [2]. In the second edition of this monograph [3], these results were generalized to the temperature dependent thermo-optic coefficient $\mathrm{d} n / \mathrm{d} T$. Unfortunately, it was done incorrectly, using an inappropriately defined refractive power of the TL. The generalization of the optical path difference (OPD) to the case of temperature dependent thermo-optic coefficient [9] is also incorrect. Extensive analysis of the thermal dependence of AE physical properties such as the thermal conductivity, thermo-optic coefficient and the expansion coefficient on the thermal aberration and thermal lensing values was performed in [10]. However, a different temperature dependence of the thermal conductivity coefficient was used in [10] and the results of [2, 3, , ] were not analysed. Besides, various temperature dependences of $\mathrm{d} n / \mathrm{d} T$ for YAG used in [2, 3, , , 9, 10] were deduced from the measurements at cryogenic temperatures and differed significantly from the recent measurement at high temperatures 18 .

In this paper, we take a closer investigation of the possibility to reduce the spherical aberration of TL in the YAG rod by the use of certain parabolic pump distribution taking into account the temperature dependence of YAG thermal and optical parameters in the temperature range from 300 to $500 \mathrm{~K}$. The general analytical solution of the heat transfer 
equation with temperature dependent thermal conductivity has been found, which allowed developing simple analytical approximations for radial temperature changes and refractive index distributions taking into account the influence of the thermal stresses [19] and end face bulging. It allowed us to carry out a detailed analysis of the dependences of spherical aberrations on different material and pump parameters. It is shown that for a certain combination of polynomial coefficients in the pump beam the fourth order aberration term could be completely removed. However, the required parabolicity of pump distribution is significantly higher than predicted in [2, 3, 不, but lower than it follows if the definition [9] of thermally induced OPD is used.

\section{General solution of heat transfer equation}

The values of thermal conductivity coefficient $k(T)$ reported in the literature are scattered in a wide range for many reasons. It depends significantly on the doping rate 20, 21]. For instance, for 0.5 at. $\%$ the Nd:YAG thermal conductivity decreases about $25 \%$ as compared with that of the undoped YAG. The temperature dependence is strong enough and can be presented by the general formula $k(T)=k_{0}\left(T_{\mathrm{r}} / T\right)^{\xi}$. Sometimes, the coefficient $\xi=0.7$ is used in calculations [10, 17]. The experimental data analysed recently in [14] is well fitted by $\xi=1.0$ in the temperature range between 160 and $500 \mathrm{~K}$. This dependence was used in [2, 6, , 9. 10, 12-16, with different values of the coefficient of thermal conductivity $k_{0}$ at the reference temperature $T_{\mathrm{r}}$. Now we think that the most validated value of $k_{0}$ is $0.105 \mathrm{~W} /(\mathrm{cm} \mathrm{K})$ at $T_{\mathrm{r}}=300 \mathrm{~K}$.

The numerical treatment of the temperature distribution in end pumped laser rods showed [13, 22] that neglecting longitudinal $z$-derivatives in the steadystate heat transfer equation with radially symmetric heating distribution does not strongly change temperature distribution for conventional (noncomposite) rods with the length $L$ significantly longer than the rod radius $R$ when rod end faces are only cooled by ambient air. Thus, neglecting the longitudinal heat flow through the end faces of $\mathrm{AE}$, the heat transfer equation becomes rather simple:

$$
\frac{1}{r} \frac{\mathrm{d}}{\mathrm{d} r}\left(k(T) r \frac{\mathrm{d} T}{\mathrm{~d} r}\right)=-Q(r) .
$$

Here $Q(r) \geq 0$ is thermal loading. For an element of cylindrical surface the heat loss by convection with the heat transfer coefficient $h$ into the cooling liquid/ water at the temperature $T_{w}$ is given by

$$
-k\left(T_{R}\right)(\partial T / \partial r)_{r=R}=h\left(T_{R}-T_{w}\right),
$$

where $T_{R}=T(R)$. The temperature distribution at the optical axis should satisfy the boundary condition

$$
(\partial T / \partial r)_{r=0}=0 .
$$

It can be easily obtained from Eqs. (1) and (2) that

$$
T_{R}=T_{\mathrm{w}}+q_{1}(R) /(h R)=T_{\mathrm{w}}+T_{h} .
$$

Here the notations $q_{1}(r)=\int_{0}^{r} Q(x) x \mathrm{~d} x$ and $T_{h}=P_{h}$ l $\left(h S_{R}\right)$ are introduced. Then $P_{h}=2 \pi L q_{1}(R)$ is the total heating power and $S_{R}=2 \pi R L$ is the area of cylindrical surface. Thus, it follows from Eq. (3) that the temperature of cylindrical surface depends on the total thermal loading only, not on its radial distribution and thermal conductivity coefficient. Now it is easy to get the general solution for temperature distribution

$$
T(r)=T_{R}\left[1+\frac{(1-\xi) q_{2}(r)}{k\left(T_{R}\right) T_{R}}\right]^{\frac{1}{1-\xi}},
$$

where

$$
q_{2}(r)=\int_{r}^{R}\left(q_{1}(x) / x\right) \mathrm{d} x .
$$

The solution for the temperature independent case $(\xi=0)$ follows easily from Eqs. (4):

$$
T(r)=T_{R}+q_{2}(r) / k_{0} .
$$

It is easy enough to get from Eq. (4a) the solution for the case when $\xi \rightarrow 1$ :

$$
T(r)=T_{R} \exp \left[q_{2}(r) /\left(k_{0} T_{\mathrm{r}}\right)\right] .
$$

Using Eqs. (4) and (5) it is easy to get particular analytical solutions for different shapes of thermal loading [6, 6, 10, 12, 13-17]. Solutions (4) and (5) are especially convenient for numerical investigations. It should be noted that the appropriate normalization of thermal loading distribution $Q(r)$ should be used in order to satisfy the equation $P_{h}=2 \pi L q_{1}(R)$. As an example, for the polynomial heating distribution

$$
Q(r)=Q_{\mathrm{p} 0} \sum_{i=0}^{m} b_{i}(r / R)^{i}
$$

on the axis heat loading should satisfy the equation

$$
Q_{\mathrm{p} 0}=\frac{P_{h}}{\pi R^{2} L} /\left(2 \sum_{i=0}^{m} \frac{b_{i}}{i+2}\right) .
$$


For the parabolic distribution $\left(b_{0,2} \neq 0\right)$ it is convenient to choose $b_{0}=1$. Then $b_{2} \geq-1$ and $Q_{\mathrm{p} 0}=P_{h} /\left[\pi R^{2} L\left(1+b_{2} / 2\right)\right]$. For the Gaussian shape

$$
Q(r)=Q_{\mathrm{G} 0} \exp \left[-2\left(r / w_{\mathrm{p}}\right)^{2}\right]
$$

the normalization constant is equal to

$$
Q_{\mathrm{G} 0}=2 P_{h} /\left\{\pi w_{\mathrm{p}}^{2} L\left[1-\exp \left(-2\left(R / w_{\mathrm{p}}\right)^{2}\right)\right]\right\},
$$

where $w_{p}$ is the radius of the pump beam. Negligence of this normalization requirement leads to a significant deviation of the calculated temperature distribution from the correct ones. So, as an example, the maximal value of temperature change $\Delta T(0) \cong 30 \mathrm{~K}$ obtained in [17] differs markedly from the correct value $\Delta T(0) \cong 37 \mathrm{~K}$ for the same parameters of the Gaussian pump. This discrepancy occurs due to the use of the incorrect normalization parameter $\bar{Q}_{\mathrm{G} 0}=P_{h} / \pi R^{2} L$, which can be obtained from Eq. $7 \mathrm{~b})$ for the case when $\varsigma=2\left(R / w_{\mathrm{p}}\right)^{2} \ll 1$. However, if parameters of [17] are used, this parameter is not small ( $\varsigma=0.5)$. Therefore, $\bar{Q}_{\mathrm{G} 0}$ is notably less than $Q_{\mathrm{G} 0}$. Further, when the truncated Gaussian distribution was approximated by the parabolic one with $b_{2}=-2 R^{2} / w_{\mathrm{p}}^{2}$, the normalization parameter $\bar{Q}_{\mathrm{G} 0}=P_{h} / \pi R^{2} L$ was used in [17] instead of $Q_{\mathrm{p} 0}$.

It is easy to evaluate that the parameter

$$
\mu(r)=\frac{(1-\xi) q_{2}(r)}{k\left(T_{R}\right) T_{R}}
$$

in Eq. (4a) for temperature distribution is small $(\mu(r) \ll 1)$ for all realistic thermal loading with $P_{h}<100 \mathrm{~W}$. Therefore, the expression for the temperature distribution (4a) can be expanded using this small parameter. For the parabolic pumping $\mu(r)=a+b \rho^{2}+c q^{4}$, where $q=r / R$ and

$$
\begin{aligned}
& a=(1-\xi) \eta\left(1+b_{2} / 4\right), \\
& b=-(1-\xi) \eta, \\
& c=-b_{2}(1-\xi) \eta / 4, \\
& \eta=\frac{P_{h}}{4 \pi L k\left(T_{R}\right) T_{R}\left(1+b_{2} / 2\right)} .
\end{aligned}
$$

Thus, the temperature distribution $T\left(X=\rho^{2}\right)=$ $T_{R}\left[1+a+b X+c X^{2}\right]^{\frac{1}{1-\xi}}$ can be approximated by the Taylor expansion as

$$
T_{a}(X)=T(X=0)+T^{\prime}(X=0) X+T^{\prime \prime}(X=0) X^{2} / 2+\ldots
$$

or

$$
T_{a}(r) \approx T_{c}+T_{2}(r / R)^{2}+T_{4}(r / R)^{4} .
$$

The derivation showed that

$$
\begin{aligned}
& T_{c}=T_{R}\left[1+(1-\xi) \eta\left(1+b_{2} / 4\right)\right]^{\frac{1}{1-\xi}}, \\
& T_{2}=-\eta T_{R}\left[1+(1-\xi) \eta\left(1+b_{2} / 4\right)\right] \frac{\xi}{1-\xi} \\
& =-\eta T_{R}\left(T_{c} / T_{R}\right)^{\xi} \\
& T_{4}=T_{2} b_{2} / 4+\eta^{2} \xi T_{c} / 2 .
\end{aligned}
$$

It should be noted that exact expressions for $T(X=0)$, derivatives $T^{\prime}(X=0)$ and $T^{\prime \prime}(X=0)$ were used in obtaining Eqs. (11). It is easy to show that Eqs. (11) can be converted to known expressions [2, 3, 凤 when $\xi \rightarrow 1$ :

$$
\begin{aligned}
& T_{c}=T_{R} \exp \left[\eta\left(1+b_{2} / 4\right)\right], \\
& T_{2}=-\eta T_{c^{\prime}} \\
& T_{4}=T_{c}\left(-\eta b_{2} / 4+\eta^{2} / 2\right) .
\end{aligned}
$$

Approximate expressions for $T_{c, 2,4}$ can be obtained from Eqs. (11) taking into account that the second terms in square brackets of Eqs. (11a) and (11b) are small enough. Then, using the expansion formula

$$
(1+x)^{\alpha}=1+\alpha x+\alpha(\alpha-1) x^{2} / 2+\ldots
$$

different expressions for $T_{c, 2,4}$ can be obtained. For example, using the first orders in Eqs. (13) it is easy to obtain the simplified expressions:

$$
\begin{aligned}
& T_{c} \cong T_{R}\left[1+\eta\left(1+b_{2} / 4\right)\right], \\
& T_{2} \cong-\eta T_{R}\left[1+\xi \eta\left(1+b_{2} / 4\right)\right] .
\end{aligned}
$$

To obtain the value of $T_{4}$ the values obtained using Eqs. (14a) and (14b) should be substituted in Eq. (11c).

The thermal loading power $P_{h}=60 \mathrm{~W}$, the radius $R=2 \mathrm{~mm}$, and the length $L=8 \mathrm{~mm}$ of the YAG rod were mainly used in the numerical simulations, if other parameters are not indicated additionally. To compare the approximations proposed in [10, 17] with ours (11), in Fig. 1 the results are presented for the thermal conductivity parameter $\xi=0.7$ used in [10, 17]. In all subsequent figures the parameter $\xi=1.0$ was used. Generally, approximate values of $T_{c, 2,4}$ (Fig. 1, curves 2) differ only slightly from the exact ones (curves 1 ). However, some questionable assumptions were made in previous papers [10, 17] during the additional approximation of these expressions. The authors of [10] assumed 


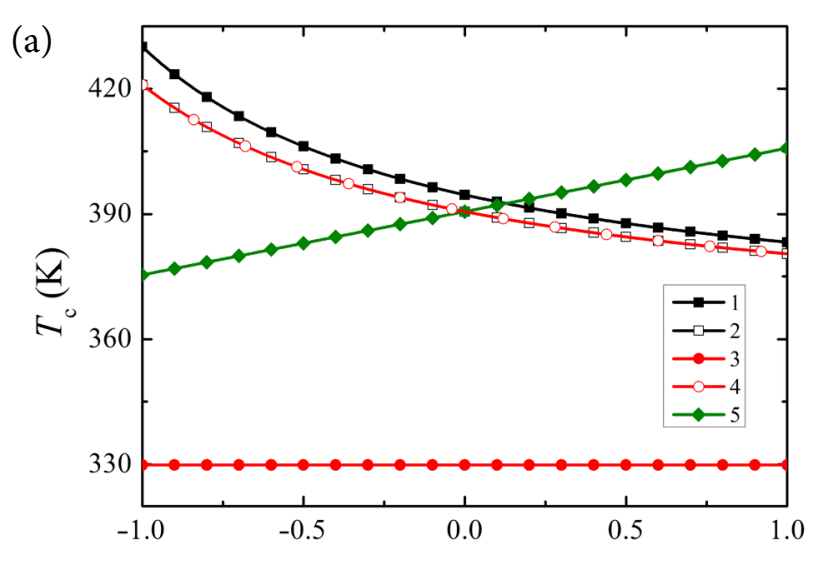

(b)

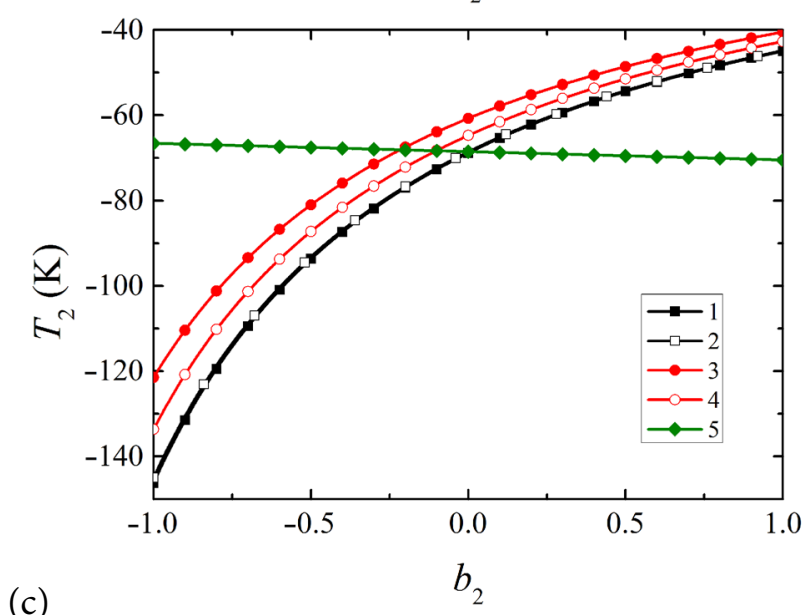

(c)

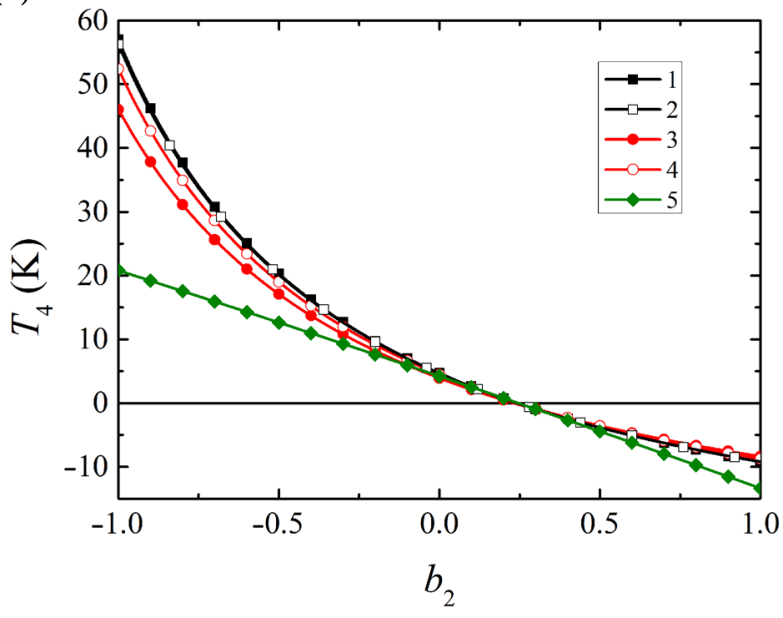

Fig. 1. Dependences of the radial temperature distribution parameters on the pump parabolicity parameter of the YAG rod with thermal loading $P_{h}=60 \mathrm{~W}$, radius $R=2 \mathrm{~mm}$ and length $L=8 \mathrm{~mm}$ taking $\xi=0.7$ and using different approximated formulae (see the text for details).

that "usually, the variation of the temperature can be considered as being small; a $20 \%$ variation between the center and the periphery of the rod would be an important gradient $\left(T_{c}-T_{R} \sim 60 \mathrm{~K}\right)$, but a small absolute variation." The lamp pumping was used in [10]. Laser diode pumping can induce much higher temperature differences between the center and the edge of the rod. Therefore, we think that the change of the ratio $T_{c} / T_{R}$ to 1 , as it is done in [10], is not justified in a general case when good accuracy is needed. Using this assumption, the authors of [10] proposed two simplifications of Eq. (14b) for $T_{2}$. In the first one, it was assumed that

$$
T_{2} \approx-\eta T_{R}
$$

though it is apparent that $T_{2} \approx-\eta T_{c}$ is better because the value $\xi=0.7$ is close enough to 1 . If the approximation $(14 \mathrm{c})$ is directly substituted to (11c), then the formula

$$
T_{4}=\frac{T_{2}^{2}}{2}\left(\frac{\xi}{T_{R}} \frac{T_{c}}{T_{R}}+\frac{b_{2}}{2 T_{2}}\right)
$$

is obtained. Then, if the ratio $T_{c} / T_{R}$ is changed to 1 , the following approximation

$$
T_{4}=\frac{T_{2}^{2}}{2}\left(\frac{\xi}{T_{R}}+\frac{b_{2}}{2 T_{2}}\right)
$$

can be obtained [10]. When Eqs. (14c) and (14e) are used, then curves 3 in Figs. 1 (b) and (c) are obtained. It is seen (Fig. 1 1(a)) that the difference between $T_{c}$ (curve 1) and $T_{R}$ (curve 3 ) is enough notable in the considered case. But if we express the $\eta=\left(T_{c}-T_{n}\right) /$ $\left[\left(1+b_{2} / 4\right) T_{R}\right]$ from Eq. (14a) and insert it in Eq. (14c), then the second (more accurate) approximation

$$
T_{2} \approx \frac{T_{c}-T_{R}}{1+b_{2} / 4}
$$

is obtained [10]. Curves 4 in Fig. 1 represent the results when Eqs. (14a), (14f) and (14e) are used in simulations. It is seen that in this case these curves are closer to curves 1 .

The authors of [17] tried to improve the accuracy of the approximations for $T_{c, 2,4}$ and to present results in the form close to the one used in [10]. Formulas (14a) and (14b) were proposed for the simulation of $T_{c, 2}$, respectively. They changed the $T_{R}$ to the $T_{c}$ in Eq. (14e), but the use of a more accurate formula (14b) for $T_{2}$ is not consistent with assumptions, by which Eq. (14b) was obtained. However, the main drawback of paper [17] is the error in the normalization of $\bar{Q}_{\mathrm{p} 0}=P_{h} / \pi R^{2} L$, which leads to the conclusion that the parameter $\eta$ does not depend on $b_{2}$ and is equal to $\bar{\eta}=\eta\left(b_{2}=0\right)$. When using this parameter in calculations, the results (curves 5) are very poor. If the correct parameter $\eta$ would be used, then the results would be rather close to the ones obtained using our formulas (11). 
The validity of this approximation can be justified if the approximation error $e_{r}=\left[T_{a}(r)-T(r)\right] / T(r)$ is low enough. For the evaluation of this error the ratio

$$
e_{R}=\left(T_{c}+T_{2}+T_{4}-T_{R}\right) / T_{R}
$$

at the edge of the rod can be used. Dependences of $e_{R}\left(b_{2}\right)$ for $\xi=0.7$ and $\xi=1.0$ were calculated using our formulas (11) and (12). This ratio does not exceed 3 and $5 \%$ for $\xi=0.7$ and $\xi=1.0$, respectively, and in the interval $0 \leq b_{2} \leq 1$ the ratio $e_{R}$ does not exceed $0.5 \%$. Thus, the developed approximation is very exact for the positive $b_{2}$ values, that are most relevant for the study of this paper.

The dependences of the temperature parameters $T_{j}\left(b_{2}\right)$ on the parabolic parameter were calculated using formulas (12) for the case $\xi=1$ and are presented in Fig. 2. It is seen that the on-axis temperature $T_{c}$ is high enough and decreases monotonically when this parameter increases. The absolute value of the parameter $T_{2}\left(b_{2}\right)$ decreases also with the increase of $b_{2}$. As it was expected, the temperature at the surface of the $\operatorname{rod} T_{R}=T_{\mathrm{w}}+T_{h}$ is constant $\left(T_{\mathrm{w}}=T_{r}\right)$ and is much lower than the on-axis temperature. It is very important that the parameter $T_{4}\left(b_{2}\right)$ changes its sign when $b_{2}$ increases. Therefore, it is evident that for the temperature independent thermooptic parameter $\mathrm{d} n / \mathrm{d} T$ there exists such value of $b_{2}$ when $T_{4}\left(b_{2}^{*}\right)=0$, i. e. the thermally induced spherical aberration can be eliminated in this case [0].

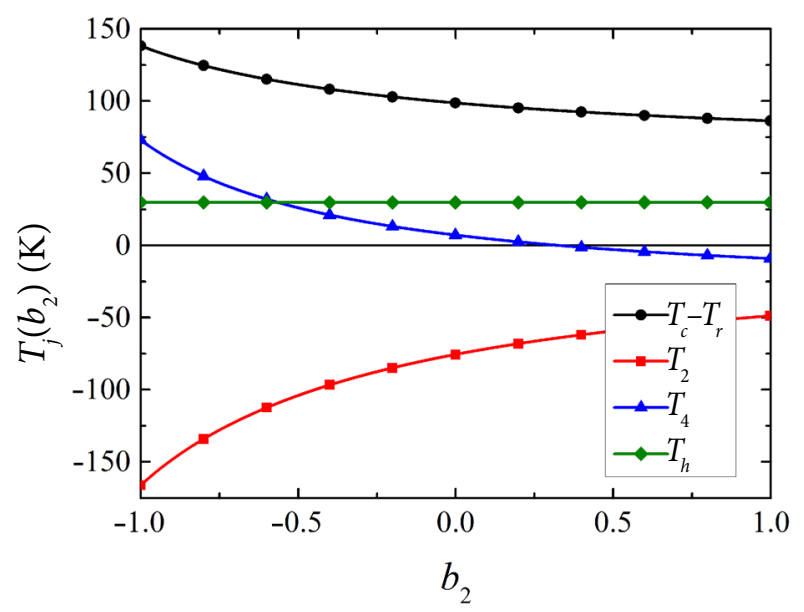

Fig. 2. Dependences of the radial temperature distribution parameters on the pump parabolicity parameter for $\xi=1$ and the same other parameters as in Fig. 1.

\section{Spherical aberrations of thermal lens}

It is seen from the obtained solutions (Fig. 2) that the radial distribution of the temperature contains forth order terms $\left(T_{4}\left(b_{2}=0\right) \neq 0\right)$ even for uniform pump sources if the temperature dependence of the thermal conductivity is taken into account. Thus, it is obvious that even for the simplest case of the temperature independent thermo-optic coefficient at zero stress $\mathrm{d} n / \mathrm{d} T \equiv(\mathrm{d} n / \mathrm{d} T)_{\sigma=0} \equiv \beta(T)[19$, the nonparabolic radial dependence of OPD occurs when the probe beam propagates through a rather short heated $\mathrm{AE}$

$$
\delta \Lambda(r)=\Lambda(0)-\Lambda(r) \approx L \beta \delta T(r)
$$

where $\Lambda(r)=n(T(r)) L$ is the optical path length at the radial coordinate $r, L$ is the length of $\mathrm{AE}$, $T(r)$ is the temperature distribution in the $\mathrm{AE}$, $n(T(r))=n\left(T_{r}\right)+\beta\left[T(r)-T_{r}\right]$ is the refractive index at the changed temperature, and $\delta T(r)=T(0)-T(r)$ is the temperature difference. Now, it is evident that for the approximate temperature distribution (10b) thermally induced OPD for the case of side pumping can be presented in the form

$$
\delta \Lambda(r)=\frac{r^{2}}{2 f_{T}}+C_{4} r^{4}+\ldots,
$$

where

$$
1 / f_{T}=-2 L \beta T_{2} / R^{2}, C_{4}=-L \beta T_{4} / R^{4} .
$$

Thus, the equation

$$
T_{4}=T_{2} b_{2} / 4+\eta^{2} \xi T_{c} / 2=0
$$

should be fulfilled for the elimination of the spherical aberration $\left(C_{4}=0\right)$. For the case of the temperature independent thermal conductivity $(\xi=0)$ Eq. (18) is fulfilled for the uniform thermal loading $b_{2}=0$ only. For brevity, we will analyse here the case of $\xi^{2}=1.0$ only. It follows from (12) that Eq. (18) is satisfied for $b_{2}=2 \eta$. This equation has two roots, but only one of them

$$
b_{2}^{*}=\sqrt{P_{h} /\left(k_{0} T_{\mathrm{r}} \pi L\right)+1}-1
$$

can be in principle physically realized, thus eliminating the spherical aberration [2, 67. It should be noted that root values (19) do not depend on the values of coefficients $\beta$ and $h$. For the above discussed YAG rod loaded with the power $P_{h}=60 \mathrm{~W}$ the parabolic coefficient $b_{2}^{*}=0.33$ is required for spherical aberration elimination.

It should be noted that the authors of the original work [ defined the refractive power $D$ first "by extending the relationship between quadratic temperature profiles and the refractive power

$$
D=-L \frac{\mathrm{d} n}{\mathrm{~d} T} \frac{\mathrm{d}^{2} T}{\mathrm{~d} r^{2}}
$$


to arbitrary temperature profiles. In general, $D$ is a function of the radius which means that the phase shift exibits higher order radial terms than quadratic ones. Having calculated $D(r)$ with Eq. (20a/9), the phase shift $\Phi$ per transit is then determined by

$$
\Phi(r)=\kappa \frac{D(r) r^{2}}{2}
$$

with $\kappa$ : wave number." The formula numbers of original texts are given after the slashes in these and following citations. In the first edition of their monograph [2] they wrote shortly: "The refractive power can be determined by using the relationship (20a/12.4)." In the second edition of the monograph [3] they wrote briefly: "The refractive power of the thermal lens is given by (20a/13.48)." The following interpretation of the defined refractive power was given in the monograph [2, p. 392]: "For a non-parabolic temperature profile, the refractive power is a function of the radius. This means that an incident ray parallel to the optical axis at a distance $r$ will intersect the optical axis at a distance $1 / D(r)$ from the principal axis of the thermal lens." There are a few inaccuracies in these definitions. First, it is easy to see that even for the temperature independent thermo-optic coefficient the definition $(20 \mathrm{~b} / 10)$

$$
\delta \Lambda^{*}(r) \equiv \frac{\lambda \Phi(r)}{2 \pi}=-L \beta\left[\frac{T_{2}}{R^{2}}+6 \frac{T_{4}}{R^{4}} r^{2}\right] r^{2}
$$

does not agree with (17). However, the requirement for "spherical aberration" elimination in (20c) is the same $-T_{4}=0$. Therefore, the same result (19) is achieved. But for the temperature dependent $\beta(T)$ the results will be different as will be shown later. Second, it can be shown that an incident ray parallel to the axis at the distance $r_{0}$ intersects the optical axis at the distance $[8,10,22]$

$$
z_{f}\left(r_{0}\right) \cong r_{0}\left(\frac{\partial \delta \Lambda(r)}{\partial r}\right)_{r_{0}}^{-1}
$$

contrary to $1 / D(r)$.

It is obvious that the temperature nonlinearity of the thermo-optic coefficient has a significant influence on the change of the refractive index and spherical aberration. We can also take into account the stress induced refractive index change [19], that also depends nonlinearly on the temperature because it contains the temperature dependent expansion coefficient $\alpha(T)$. The reviews of the earlier published values for the thermo-optic coefficient $\beta(T)$ and expansion coefficient $\alpha(T)$ have been given in [22, 23]. We will mainly use the recently published values in [18], because this reference provides temperature-dependent data in the tem- perature range $300-600 \mathrm{~K}$. It is obvious that in the short enough temperature range from 300 to $500 \mathrm{~K}$ the linear approximation of these coefficients can be used:

$$
\begin{aligned}
& \alpha(T)=\alpha_{1}+\alpha_{2} \widetilde{T}, \alpha_{1}=\alpha\left(T_{\mathrm{r}}\right), \alpha_{2}=(\mathrm{d} \alpha / \mathrm{d} T)_{T=T_{\mathrm{r}}}, \\
& \beta(T)=\beta_{1}+\beta_{2} \widetilde{T}, \beta_{1}=\beta\left(T_{\mathrm{r}}\right), \beta_{2}=(\mathrm{d} \beta / \mathrm{d} T)_{T=T_{\mathrm{r}}} .
\end{aligned}
$$

Here $\Delta T \equiv \widetilde{T}=T-T_{\mathrm{r}}, T_{\mathrm{r}}=300 \mathrm{~K}$.

The data of [18] and from previous papers [3, 9 , 10] are presented in Fig. 3. It is seen that the values of these coefficients differ significantly. The approximation $\alpha(T)=\alpha^{*}+\alpha_{2} T$ with $\alpha^{*}=-1.78$ and $\alpha_{2}=0.033 \mathrm{~K}^{-1}$ in units of $\mathrm{ppm} / \mathrm{K}$ upper blue line with triangle symbols (line 4) has been criticized in [24] because of its negative value for $T=0$ even though this fit produces values near room temperature closer to the reported
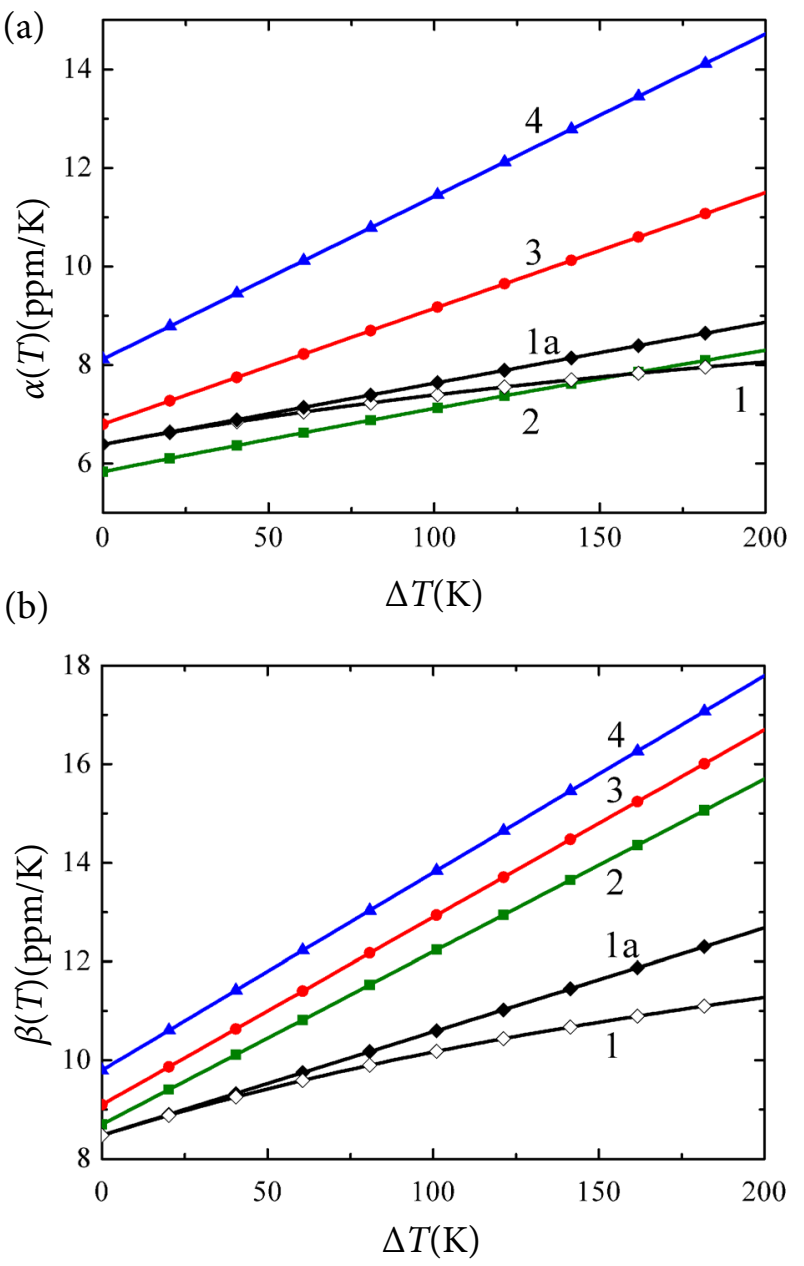

Fig. 3. Linear approximations of temperature dependence of the expansion coefficient (a) and the thermo-optic coefficient (b) used previously (line 4 (blue online) is updated data from [3], line 3 (red) shows data from [9], line 2 (green) is data from [10]) and used in this paper (line 1a), which was extracted from recently published data (curve 1 from [18]). 
single-point measurements. Therefore, the author of [24] prefers to use another approximation, which underestimates the thermal expansion coefficient of YAG at room temperature but satisfies that $\alpha \rightarrow 0$ as $T \rightarrow 0$, as required by theory. Thus, it is seen that the approximations of data from [18] give the lowest values for $\alpha_{1,2}$ and $\beta_{1,2}$ as compared with values used in previous papers.

The YAG crystal, while cubic, is nearly isotropic [19]. Therefore, only the knowledge of the Young's modulus $E$ and the Poisson's ratio $v$ is needed. It was shown [25] that $E$ and $v$ change no more than by 7 and $2 \%$, respectively, across the cryogenic range 140-298 K. Therefore, we have assumed that they are also constant in the range $300-500 \mathrm{~K}$ and have the values $E=280 \mathrm{GPa}$ and $v=0.26$ [19].

Calculation of the photoelastic effect contribution to the thermally induced refractive index change requires the values of elastooptic coefficients $p_{i j}[19]$, which are also temperature dependent, in principle [26]. However, the data from [27] is only referenced in the literature for $p_{i j}$ values, and their temperature dependence has not been investigated till now.

A simple expression for the refractive index change in the plane strain approximations has been recently found [19] for the temperature independent parameters of $\mathrm{AE}$

$$
n_{r, \theta}=n_{0}-A_{1} T^{(R)}+\left[\beta+A_{1}\right] \widetilde{T} \pm A_{2}\left[T^{(r)}-\widetilde{T}(r)\right],
$$

where $n_{0}$ is the initial refractive index, $R$ is the radius of $\mathrm{AE}, A_{1}=\alpha a_{1}, A_{2}=\alpha a_{2}$, upper (+) and lower (-) signs describe the radial and tangential components of the index change and

$$
\begin{aligned}
& T^{(r)}=\left(2 / r^{2}\right) \int_{0}^{r} \widetilde{T}(r) r \mathrm{~d} r, \\
& a_{1}=\frac{n_{0}^{3}}{6(1-v)}\left[2(1-2 v)\left(p_{11}+2 p_{12}\right)\right. \\
& \left.-(1+v) p_{44}\right], \\
& a_{2}=\frac{n_{0}^{3}}{12(1-v)}(1+v)\left(p_{11}-p_{12}+4 p_{44}\right) .
\end{aligned}
$$

The generalization of (22) to temperature dependent parameters may be made by the use of adiabatic transition from small to finite temperature changes. For a very small temperature change $\widetilde{T}=\mathrm{d} \widetilde{T}(r)$ the index change is expressed by

$$
\begin{aligned}
& \mathrm{d} n_{r, \theta}(\widetilde{T}(r))=-a_{1} \alpha(\widetilde{T}) \mathrm{d} T^{(R)}+[\beta(\widetilde{T}) \\
& \left.+a_{1} \alpha(\widetilde{T})\right] \mathrm{d} \widetilde{T}(r) \pm a_{2}\left[\alpha(\widetilde{T}) \mathrm{d} T^{(r)}-\alpha(\widetilde{T}) \mathrm{d} \widetilde{T}(r)\right]
\end{aligned}
$$

For a finite temperature change $\widetilde{T}(r)$ the total refractive index change can be found by the integration of Eq. (23a)

$$
n_{r, \theta}(r)=n_{0}-a_{1} \alpha_{\Sigma}^{(R)}+\beta_{\Sigma}+a_{1} \alpha_{\Sigma} \pm a_{2}\left[\alpha_{\Sigma}^{(r)}-\alpha_{\Sigma}\right]
$$

where

$$
\begin{aligned}
& \alpha_{\Sigma}=\int_{0}^{\widetilde{T}} \alpha(T) \mathrm{d} T, \quad \beta_{\Sigma}=\int_{0}^{\widetilde{T}} \beta(T) \mathrm{d} T, \\
& \alpha_{\Sigma}^{(r)}=\left(2 / r^{2}\right) \int_{0}^{r} \alpha_{\Sigma} r \mathrm{~d} r .
\end{aligned}
$$

Using Eq. (10b) for the temperature distribution and the linear approximation for $\alpha(T)$ and $\beta(T)$, it is easy to find

$$
\begin{aligned}
& \alpha_{\Sigma} \approx \alpha_{1} \widetilde{T}+\alpha_{2} \widetilde{T}^{2} / 2 \approx \alpha_{1}\left[T_{0}+T_{2}(r / R)^{2}+T_{4}(r / R)^{4}\right] \\
& +\left(\alpha_{2} / 2\right)\left[T_{0}^{2}+2 T_{0} T_{2}(r / R)^{2}+\left(2 T_{0} T_{4}+T_{2}^{2}\right)(r / R)^{4}\right], \quad(24 \mathrm{a}) \\
& \beta_{\Sigma} \approx \beta_{1} \widetilde{T}+\beta_{2} \widetilde{T}^{2} / 2 \approx \beta_{1} T_{0}+\beta_{2} T_{0}^{2} / 2+\left(\beta_{1} T_{2}+\beta_{2} T_{0} T_{2}\right)(r / R)^{2} \\
& +\left(\beta_{1} T_{4}+\beta_{2} T_{0} T_{4}+\beta_{2} T_{2}^{2} / 2\right)(r / R)^{4},
\end{aligned}
$$

where $T_{0}=T_{c}-T_{\mathrm{r}}$ and $T_{\mathrm{w}}=T_{\mathrm{r}}$ is assumed for short. Inserting (24) in $\alpha_{\Sigma}^{(r)}$, it follows:

$$
\begin{aligned}
& \alpha_{\Sigma}^{(r)} \approx \alpha_{1} T_{0}+\alpha_{2} T_{0}^{2} / 2+\left(\alpha_{1} T_{2} / 2+\alpha_{2} T_{0} T_{2} / 2\right)(r / R)^{2} \\
& +\left(\alpha_{1} T_{4} / 3+\alpha_{2} T_{0} T_{4} / 3+\alpha_{2} T_{2}^{2} / 6\right)(r / R)^{4} .
\end{aligned}
$$

Now, Eq. (23b) can be approximated as

$$
n_{r, \theta}(r)=N_{r, \theta}^{(0)}+N_{r, \theta}^{(2)}(r / R)^{2}+N_{r, \theta}^{(4)}(r / R)^{4},
$$

where the following expressions for coefficients in Eq. (25a) are found:

$$
\begin{aligned}
& N_{r, \theta}^{(0)}=n\left(T_{\mathrm{r}}\right)+\left[\beta_{1} T_{0}+\beta_{2} T_{0}^{2} / 2+a_{1}\left(\alpha_{1} T_{0}+\alpha_{2} T_{0}^{2} / 2\right)\right], \\
& N_{r, \theta}^{(2)}=\left(\beta_{1}+\beta_{2} T_{0}\right) T_{2}+a_{1}\left(\alpha_{1}+\alpha_{2} T_{0}\right) T_{2} \\
& \mp a_{2}\left(\alpha_{1}+\alpha_{2} T_{0}\right) T_{2} / 2, \\
& N_{r, \theta}^{(4)}=\beta_{1} T_{4}+\beta_{2} T_{0} T_{4}+\beta_{2} T_{2}^{2} / 2+a_{1}\left(\alpha_{1} T_{4}+\alpha_{2} T_{0} T_{4}+\alpha_{2} T_{2}^{2} / 2\right) \\
& \mp a_{2}\left(2 \alpha_{1} T_{4}+2 \alpha_{2} T_{0} T_{4}+\alpha_{2} T_{2}^{2}\right) / 3 .
\end{aligned}
$$

If the bulging of end faces of $\mathrm{AE}$ is taken into account, then $a_{1}$ should be changed to $a_{1}^{*}=$ $a_{1}+(1+v)\left(n_{0}-1\right) C_{\mathrm{bg}}$, where the coefficient $C_{\mathrm{bg}}\left(0 \leq C_{\mathrm{pg}} \leq 1\right)$ allows taking into account end face bulging [9, 28]. It is important to note that for the rod type $\mathrm{AE}$ the contribution of face bulging to OPD is a few times smaller as compared to the contribution due to index change. 
If the change of the refractive index depends on the longitudinal coordinate $z$, then the total OPD for the given $r$ can be found by integrating the appropriate expression along the $z$. It should be noted that the so-called generalized (temperature independent) thermo-optic coefficients $\chi_{r, \theta}$ are often used [5, 19, for the radial and tangential OPD calculation:

$$
\delta \Lambda_{r, \theta}(r)=\int_{0}^{L} \chi_{r, \theta} \delta T(r, z) \mathrm{d} z .
$$

But the generalization of Eq. (26) on the temperature dependent case proposed in [22] and later used in [8, formula (43)]

$$
\delta \Lambda(r)=\Delta \Lambda(0)-\Delta \Lambda(r), \Delta \Lambda(r)=\int_{0}^{L} \chi(T) T(r, z) \mathrm{d} z,
$$

where

$$
\chi(T)=\beta(T)+C_{\alpha}\left(n_{0}-1\right)(1+v) \alpha(T), 0<C_{\alpha}<1,
$$

is incorrect as it can be easily seen from the derivation of Eq. (25). Besides, the use of $T(r, z)$ in Eq. (27a) instead of $\widetilde{T}(r, z)$ may increase the value of local OPD several times.

The influence of the expansion coefficient $\alpha(T)$ was not taken into account in [2, 3, , 7 . It is easy to get required expressions taking in formulas (25) $\alpha_{1}=\alpha_{2}=0$. In this case the change of the refractive index is the same for both polarizations and the coefficient of the spherical aberration is

$$
N^{(4)}\left(b_{2}\right)=\beta_{1} T_{4}+\beta_{2} T_{0} T_{4}+\beta_{2} T_{2}^{2} / 2 .
$$

Authors of [10] started with the expression (B.12), which in our notation can be written as

$$
\Delta n_{T}(r)=\beta\left(T_{c}\right)\left[\left(T(r)-T_{c}\right)\right]+\frac{\beta_{2}}{2}\left[T(r)-T_{c}\right]^{2} .
$$

Taking into account that $\beta\left(T_{c}\right)=\beta_{1}+\beta_{2}\left(T_{c}-T_{c}\right)$, the same expressions (28a) are obtained from Eq. (29).

If "optical power" defined in [2, , , , \#] is used for the investigation of the possibility to eliminate spherical aberration, then Eq. (20a) is expressed as

$$
D(r)=-L \frac{\mathrm{d} n}{\mathrm{~d} T} \frac{\mathrm{d}^{2} T(r)}{\mathrm{d} r^{2}}=D_{0}\left[1-\gamma\left(\frac{r}{R}\right)^{2}\right],
$$

where

$$
\gamma=-\frac{3}{2} b_{2}+3 \eta+\frac{\eta \beta_{2} T_{c}}{(\mathrm{~d} n / \mathrm{d} T)_{T_{c}}}
$$

coincides with the formula (13.52) from [3]. Equation (30b) can be written as

$$
\gamma=-\frac{6 N^{(4-)}\left(b_{2}\right)}{\left(\beta_{1}+\beta_{2} T_{0}\right) T_{2}},
$$

where

$$
N^{(4-)}\left(b_{2}\right)=\beta_{1} T_{4}+\beta_{2} T_{0} T_{4}+\beta_{2} T_{2}^{2} / 6 .
$$

Thus, the condition $\gamma=0$ proposed in [3] for elimination of the spherical aberration is equivalent to $N^{(4-)}\left(b_{2}\right)=0$. If the definition of OPD from [9] would be used, then the coefficient

$$
N^{(4+)}\left(b_{2}\right)=\beta_{1} T_{4}+2 \beta_{2} T_{0} T_{4}+\beta_{2} T_{2}^{2}
$$

should be equal to zero for the elimination of spherical aberrations. So, it is seen that Eqs. (28a) and (28b) differ by the last term, just like Eq. (28c) where additionally the second term is magnified by a factor of 2 . Thereby, approximations (11), (12) or (14) for coefficients $T_{0,2,4}$ can be applied when using formulas (28) for different cases of the temperature dependence of the conductivity coefficient.

\section{Possibility of elimination of spherical aberrations}

We discuss the possibility to eliminate the spherical aberration for the case of $k\left(T_{\mathrm{r}}\right)=k_{0}$ and $\beta_{2} \neq 0$ first. It should be noted that values of $T_{0,2,4}$ depend significantly (through $T_{R}$ ) on the value of $h$ or nondimensional $a_{h}=k_{0} /(2 h R)$. This change should be generally taken into account during calculation of $b_{2}$ values, at which spherical aberration is eliminated $\left(N^{(4)}\left(b_{2}\right)=0\right)$. For the case of constant thermal conductivity and constant loading $Q_{\mathrm{p} 0}$ at the axis of $\mathrm{AE}$ the parameter $\eta$ does not depend on $b_{2}$, and the parameters $T_{0}=T_{h}+\left(1+b_{2} / 4\right) \eta T_{\mathrm{r}} T_{h}=4 a_{h}\left(1+b_{2} / 2\right) \eta T_{\mathrm{r}^{\prime}}$ $T_{2}=-\eta T_{\mathrm{r}}$ and $T_{4}=-\eta b_{2} T_{\mathrm{r}} / 4$ are the linear functions of $b_{2}$. Therefore, the equation $N^{(4)}\left(b_{2}\right)=0$ can be presented as

$$
A b_{2}^{2}+B b_{2}+C=A\left[b_{2}+B /(2 A)\right]^{2}+C-B^{2} /(4 A)=0,(31 \mathrm{a})
$$

where

$$
\begin{aligned}
& A=-\left(a_{h}+1 / 8\right) C, B=\beta_{1} T_{2} / 4-2\left(a_{h}+1 / 4\right) C, \\
& C=\beta_{2} T_{2}^{2} / 2 .
\end{aligned}
$$

Taking into account that $a_{h}>0$ and $T_{2}<0$, it is easy to see that $A<0, B<0, C>0, C-B^{2} /(4 A)>0$. Therefore, Eq. (31a) should have two different real roots:

$$
b_{2}^{(1,2)}=\left[-B \pm \sqrt{B^{2}-4 A C}\right] / 2 A .
$$

The solution should satisfy the necessary conditions: $Q(r) \geq 0$ and $\widetilde{T}(r) \geq 0$. Using values $\beta_{1}=8.48 \times 10^{-6} \mathrm{~K}^{-1}$ and $\beta_{2}=0.021 \times 10^{-6} \mathrm{~K}^{-2}$ extracted from the data of [18], 
it is easy to find for the fixed $Q_{p 0}=0.6 \mathrm{~W} / \mathrm{mm}^{3}$ that only one root $b_{2}^{(2)} \equiv b_{2}^{*} \approx C /|B|=0.23$ satisfies the condition $Q(r) \geq \beta$. This result belongs to the case with $a_{h}=0.13$ (Fig. 4). It is seen that values of $b_{2}^{*}$ differ notably for different $a_{h}$. The line with $a_{h}=0$ corresponds to the case of the boundary condition of the first kind when temperature at the periphery of the rod is equal to the ambient temperature $T_{r}$. Thus, the decrease of the convection heat transfer coefficient $h$ results in the decrease of $b_{2}^{*}$ coefficients. In general, using Eq. (32) we can find roots $b_{2}^{*}$ for different pump densities at the axis of AE and different coefficients of heat transfer (Fig. 4). Using this data, roots for the given fixed power can be found. As an example, the root $b_{2}^{*}=0.23$ corresponds to powers $P_{h}\left(b_{2}^{*}\right)=\pi R^{2} L Q_{\mathrm{p} 0}$ $\left(1+b_{2}^{\star} / 2\right) \approx 66.6 \mathrm{~W}$, but for the thermal load $P_{h}=60 \mathrm{~W}$ the corresponding $b_{2}^{*}=0.21$. It should be noted that the cases of the fixed pump power density at the axis of $\mathrm{AE}$ are important for the investigation of situations when the elimination of spherical aberration must be realized for the given on-axis inversion of active ion population. It follows from the above results that the influence of the temperature dependence of thermal conductivity at $\beta_{2}=0$ is stronger $\left(b_{2}^{*}=0.33\right)$ than the influence of $\beta_{2}$ at constant conductivity $\left(b_{2}^{*}=0.21\right)$ for the same values of parameters used.

It should be noted that more complicated equations need to be solved in the general case instead of the quadratic equation (31) for $b_{2}^{*}$. Therefore, a simple numerical method was used to find required roots. Graphics of spherical aberration coefficients (25d) and (28) are presented in Fig. 5 for $\xi=1.0, C_{\mathrm{bg}}=0, P_{h}=60 \mathrm{~W}$ and various values of $\alpha_{j}, \beta_{j}$ parameters. Nonzero values

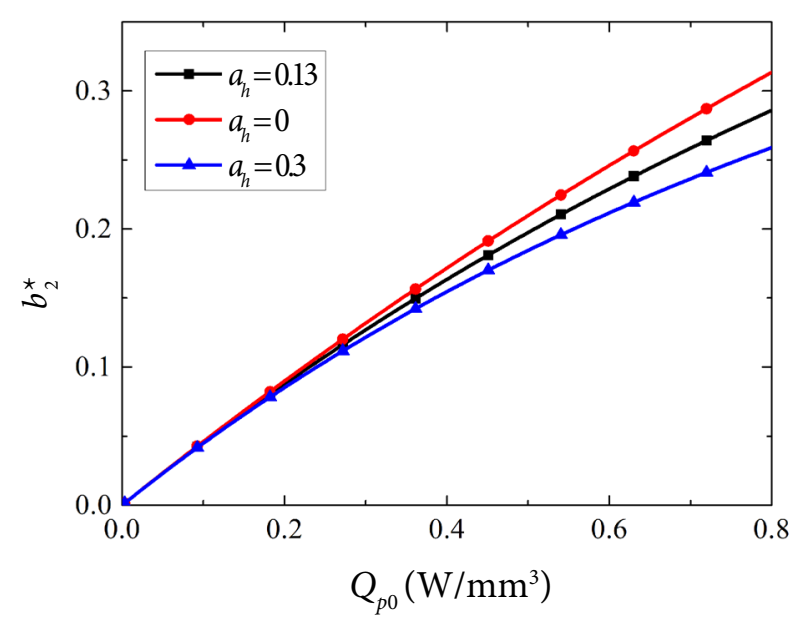

Fig. 4. Dependence of the critical parabolicity parameter required for spherical aberration elimination for pump beams with given thermal loading density at the rod axis for different heat transfer coefficients in the case of constant thermal conductivity. of these parameters are obtained using the data from 18p: $\alpha_{1}=6.39, \alpha_{2}=0.0124, \beta_{1}=8.48, \beta_{2}=0.021$ in ppm $\left(1 \mathrm{ppm}=10^{-6}\right)$. Intersections of these curves with the $x$ axis give the required values of $b_{2}^{*}$. Curve 1 corresponds to $\beta_{1} \neq 0, \beta_{2}=\alpha_{1}=\alpha_{2}=0$ and follows from all expressions for the aberration coefficients. The $b_{2}^{*} \approx 0.33$ in this case (see Eq. (19)) does not depend on $\beta_{2}$. Curve 2 was calculated using Eq. (28b) and $\alpha_{1}=\alpha_{2}=0$. Thus, the nonzero value of $\beta_{2}$ increases the value of $b_{2}^{*} \approx 0.40$ only slightly if the requirement for elimination of spherical aberration is used from [ 3 ]. Curve 3 presents results when the arguably correct formula (28a) and $\alpha_{1}=\alpha_{2}=0$ are used. So, the required parabolicity coefficient $b_{2}^{*} \approx 0.535$ increases notably as compared with the previous incorrect value $b_{2}^{*} \approx 0.40$. The changes of $b_{2 \mathrm{r}}^{*} \approx 0.530$ and $b_{2 \theta}^{*} \approx 0.537$ due to the contribution of the photoelastic effect $\left(\alpha_{1} \neq 0, \alpha_{2} \neq 0\right)$ for radial (curve $3 \mathrm{a}$ ) and tangential (curve $3 \mathrm{~b}$ ) polarizations are very small as compared with the results of curve 3 . The incorrect definition of OPD (27) for the case of the temperature dependent thermo-optic coefficient $\left(\beta_{1} \neq 0, \beta_{2} \neq 0\right)$ leads to the overrated value $b_{2}^{*} \approx 0.665$ (curve 4) even neglecting the contribution of the photoelastic effect $\left(\alpha_{1}=0, \alpha_{2}=0\right)$.

By the same manner the dependence of corresponding roots $b_{2}^{*}$ on the thermal loading powers can be found (Fig. 6). It is seen that taking into account the temperature dependence of thermo-optic

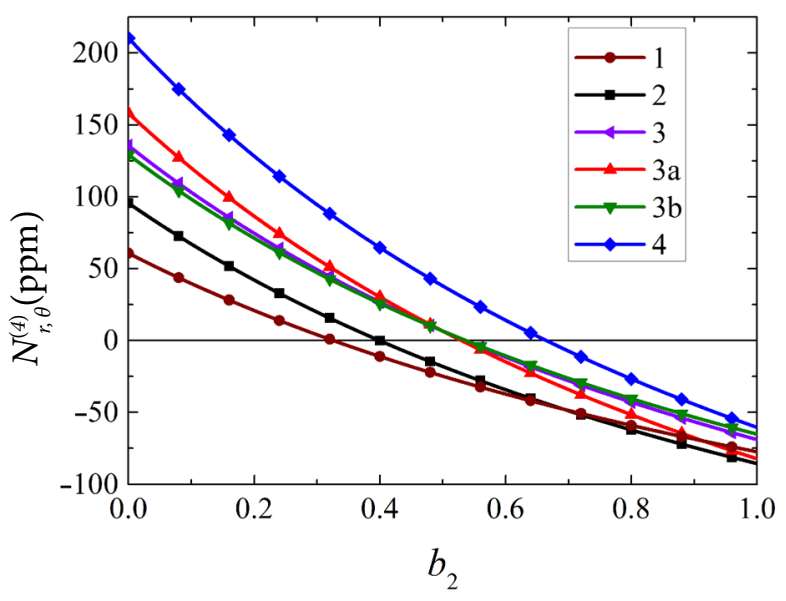

Fig. 5. Dependences of forth order polynomial coefficients of the thermally induced refractive index on the pump parabolicity coefficient for fixed total loading power $60 \mathrm{~W}$ and different expressions for the optical path difference: curve 1 (brown online) from $[2,7]$, curve 2 from [3], curve 4 (blue) from [9] and curves 3 (violet), 3a (red) and $3 \mathrm{~b}$ (green) [formulas of this paper]. Curves $3 \mathrm{a}$ and $3 \mathrm{~b}$ correspond to radial and tangential polarizations, when the temperature dependence of the expansion coefficient is taken into account. 


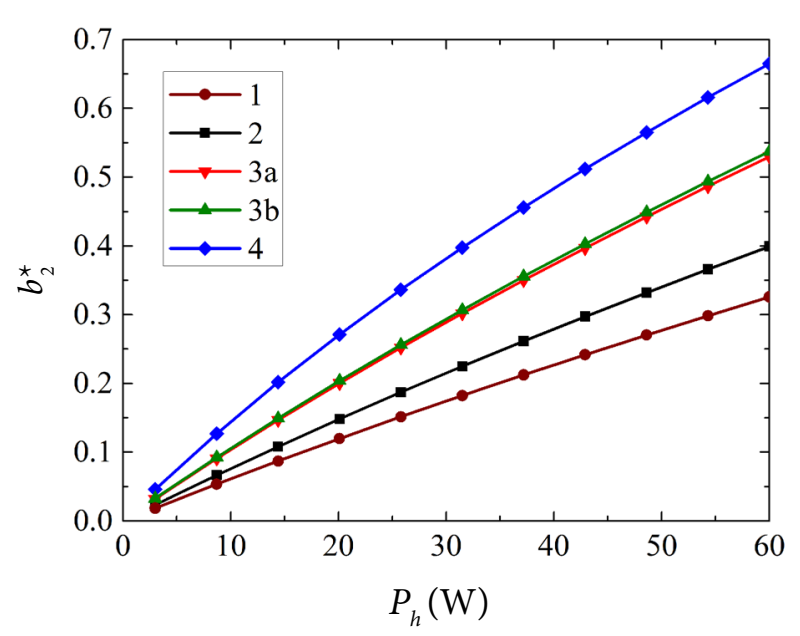

Fig. 6. Dependence of critical parabolicity parameter on the thermal loading power. The curve numbers are the same as in Fig. 5.

$\beta(T)$ and thermal expansion $\alpha(T)$ coefficients significantly enhanced $b_{2 \mathrm{r}}^{*}$ (curve $3 \mathrm{a}$ ) and $b_{2 \mathrm{r} \theta}^{*}$ (curve $3 \mathrm{~b}$ ) values as compared with the corresponding values $b_{2}^{*}$ for the case of the temperature independent thermo-optic coefficient $\beta\left(T_{r}\right)$ investigated in 仍 first, when the photoelastic effect was neglected (curve 1). It should be noted that incorrect generalization [3] to the case of $\beta(T)$ gives higher values of $b_{2}^{*}$ (curve 2), but significantly lower than the correct ones. It should be noted that the difference between $b_{2 r}^{*}$ and $b_{2 \theta}^{*}$ is very small although the thermally induced birefringence $\delta n(r)=n_{r}(r)-n_{\theta}(r)$ is notable enough. The use of the generalized OPD definition [9] gives markedly higher values of $b_{2}^{*}$ (curve 4). Thus, the correct definition of OPD for temperature dependent parameters leads to higher values of $b_{2}^{*}$ (curves $3 \mathrm{a}$ and $\mathrm{b}$ ) than follows (curve 2) from the incorrect definition of optical power [3] and lower values as compared with the corresponding values (curve 4) if the definition proposed in [9] of OPD is used.

In the conference paper [29], without reference to [2,3, \#, the optical path difference is defined as in (16) for the temperature independent thermo-optic coefficient $\partial n / \partial T$. Thus, it is assumed that "an important source of spherical-aberration arises from the thermal-conductivity's temperature dependence". For a uniformly pumped rod this dependence results in a nonparabolic temperature and refractive index distribution. It is also stated that "there is, however, no reason why the pump light distribution must be constant" because "the pump-distribution could be controlled by varying the mechanical dimensions (of the pumpchamber) as well as the rod doping." Thus, the authors of [29] believed that " $T_{4}=0$ (in our notation) should yield a spherical-aberration free pump-chamber." It was shown with the aid of a two-dimensional MonteCarlo based simulation package that by increasing the rod-doping a dip could be generated in the pump distribution, and the coefficient $T_{4}=0$ for the "STAR" pump-chamber with the rod $\mathrm{Nd}$ doping $0.8 \%$ can be achieved at a heat power of $1050 \mathrm{~W}$ [29]. As follows from the results discussed above, the condition $T_{4}=0$ is not sufficient for the elimination of spherical aberration. The authors of [10] believed that the cooling temperature of LD bars determines the emission wavelength of the diodes, and as a consequence allows to vary the $b_{2}$ parameter of pump power distribution. However, the presented pump profiles of the laser head show the uniform and dome type distributions. In the recent paper [30] it is also shown that by changing the shape of the octagonal microchip or $\mathrm{Yb}$ doping the absorption distribution with a dip in the central region of the rod may be obtained. Thus, the required pump beam profile for the elimination of spherical aberration may be realized in principle, though it may be a rather complicated experimental task.

\section{Conclusions}

In this paper, we presented a detailed analysis of the main mechanisms which contribute to the spherical aberrations of the thermal lens induced in YAG $\mathrm{AE}$ under different radial shapes of thermal loading. The analytical solution of the heat transfer equation with the general enough temperature dependence of the thermal conductivity coefficient is found in the integral form, which is especially convenient for a numerical analysis of the radial temperature distribution. It is shown that a small expansion parameter exists for the real value of thermal loading, which allows getting a simple, but very exact analytical presentation of radial temperature distribution in the form of the Taylor series expansion. This expansion allowed calculating the refractive index change taking into account the temperature dependence of the thermo-optic coefficient, the coefficient of linear thermal expansion and the contribution due to the photoelastic effect. The analytical expressions for the radial dependence of the optical path difference are found using a linear approximation of the recent measurements of the change of the expansion coefficient and the thermo-optic coefficient at high temperatures.

The inaccuracies in the previously used definitions of the optical path difference for the case of the temperature dependent thermo-optic coefficient are discussed. It is shown that the use of these definitions significantly changes the values of the parabolic coefficient at which the elimination of spherical aberration may 
be realized. It is noted that the values of the thermal conductivity and the thermo-optic coefficient of the YAG crystal used in the previous works were significantly larger than recently measured. Therefore, the temperature dependence of the thermo-optic coefficient is not the principal cause for thermal spherical aberration, as was stated previously. Both dependences with the temperature of the thermal conductivity coefficient and the thermo-optic coefficient are nearly equally important for the origin of spherical aberration. It is shown that the use of the correct definition of OPD for temperature dependent parameters leads to higher values of the parabolicity parameter of the pump distribution required for the spherical aberration elimination than followed from the incorrect definition of optical power [3] and to lower values as compared with the corresponding values if the definition of OPD proposed in [9] is used. It is shown that the elimination of the spherical aberration for radial polarization leads to a practically total elimination of the spherical aberration for tangential polarization, and vice versa. Thus, the elimination of thermally induced spherical aberration by a proper choice of the pump beam profile is possible in principle though it may be a more difficult experimental task due to notably higher values of the parabolicity parameter that are required.

\section{References}

[1] A.V. Mezenov, L.N. Soms, and A.I. Stepanov, Thermooptics of solid-state lasers, J. Russ. Laser Res. 8(5), 427-549 (1987).

[2] N. Hodgson and H. Weber, Laser Resonators and Beam Propagation: Fundamentals, Advanced Concepts and Applications (Springer, Berlin, 1997).

[3] N. Hodgson and H. Weber, Laser Resonators and Beam Propagation: Fundamentals, Advanced Concepts and Applications, 2nd ed. (Springer, Berlin, 2005).

[4] W. Koechner, Solid-State Laser Engineering, 6th Revised and Updated Ed. (Springer, Berlin, 2006).

[5] S. Chénais, F. Druon, S. Forget, F. Balembois, and P. Georges, On thermal effects in solid-state lasers: The case of ytterbium-doped materials, Prog. Quantum Electron. 30(4), 89-153 (2006).

[6] A.G. Rozanov, Nonlinear model of thermal effects in YAG:Nd laser crystals, Sov. J. Quantum Electron. 21(10), 1074-1075 (1992).

[7] N. Hodgson and H. Weber, Influence of spherical aberration of the active medium on the performance of Nd:YAG lasers, IEEE J. Quant. Electron. 29(3), 2497-2507 (1993).

[8] W.A. Clarkson, Thermal effects and their mitigation in end-pumped solid-state lasers, J. Phys. D 34(16), 2381-2395 (2001).
[9] S. Bjurshagen and R. Koch, Modeling of energytransfer upconversion and thermal effects in end-pumped quasi-three-level lasers, Appl. Opt. 43(24), 4753-4767 (2004).

[10] A.M. Bonnefois, M. Gilbert, P.Y. Thro, and J.M. Weulersse, Thermal lensing and spherical aberration in high-power transversally pumped laser rods, Opt. Commun. 259(1), 223-235 (2006).

[11]X. Song, B. Li, Z. Guo, S. Wang, D. Cai, and J. Wen, Influences of pump beam distribution on thermal lensing spherical aberration in an LD end-pumped Nd:YAG laser, Opt. Commun. 282(24), 4779-4783 (2009).

[12] A.M. Rodin, A. Michailovas, A.S. Dementjev, and A. Aleknavicius, Beam quality investigation in Nd:YAG crystal fiber amplifier pumped at $>110 \mathrm{~W}$, Proc. SPIE 9342, 934207 (2015).

[13] A.S. Dement'ev, A. Jovaiša, K. Račkaitis, F. Ivanauskas, and J. Dabulytė-Bagdonavičiené, Numerical treatment of the temperature distribution in endpumped composite laser rods, Lith. J. Phys. 47(3), 279-288 (2007).

[14] G.L. Bourdet and H. Yu, Longitudinal temperature distribution in an end-pumped solid-state amplifier medium: application to a high average power diode pumped Yb:YAG thin disk amplifier, Appl. Opt. 46(23), 6033-6041 (2007).

[15] G.L. Bourdet and C. Gouédard, Simple analytical derivations of thermal lensing in longitudinally Q-CW pumped Yb:YAG, Appl. Opt. 49(22), 41604167 (2010).

[16]M.M. Tilleman, Analysis of temperature and thermo-optical properties in optical materials. 1: Cylindrical geometry, Opt. Mater. 33(1), 48-57 (2010).

[17] M.H.M. Dindarlu, A. Maleki, H. Saghafifar, M.K. Tehrani, and S. Baghali, Analytical model for temperature, stress and strain distribution inside a side-pumped Nd:YAG laser rod having a Gaussian pump profile, Laser Phys. 25(4), 045001 (2015).

[18]H. Furuse, R. Yasuhara, and K. Hiraga, Thermooptic properties of ceramic YAG at high temperatures, Opt. Mater. Express 4(9), 1794-1799 (2014).

[19]A.S. Dementev, Relationships between different expressions of thermo-optic and photoelastic coefficients of YAG crystal, Laser Phys. 25(9), 095004 (2015).

[20] B.S. Wang, H.H. Jiang, and S.T. Yin, Thermal conductivity of synthetic garnet laser crystals, Eur. Phys. J. Appl. Phys. 39(1), 23-26 (2007).

[21] Y. Sato, J. Akiyama, and T. Taira, Effects of rareearth doping on thermal conductivity in $\mathrm{Y}_{3} \mathrm{Al}_{5} \mathrm{O}_{12}$ crystals, Opt. Mater. 31(5), 720-724 (2009).

[22] M. Polnau, P.J. Hardman, M.A. Kern, W.A. Clarkson, and D.C. Hanna, Upconversion-induced heat generation and thermal lensing in Nd:YLF 
and Nd:YAG, Phys. Rev. B 58(24), 16076-16092 (1998).

[23] R.L. Aggarwal, D.J. Ripin, J.R. Ochoa, and T.Y. Fan, Measurement of thermo-optical properties of $\mathrm{Y}_{3} \mathrm{Al}_{5} \mathrm{O}_{12}, \mathrm{Lu}_{3} \mathrm{Al}_{5} \mathrm{O}_{12}, \mathrm{YAlO}_{3}, \mathrm{LiYF}_{4}, \mathrm{LiLuF}_{4}, \mathrm{BaY}_{2} \mathrm{~F}_{8}$, $\mathrm{KGd}\left(\mathrm{WO}_{4}\right)_{2}$, and $\mathrm{KY}\left(\mathrm{WO}_{4}\right)_{2}$ laser crystals in the 80-300 K temperature range, J. Appl. Phys. 98, 103514 (2005).

[24]D.C. Brown, Nonlinear thermal and stress effects and scaling behaviour of YAG slab amplifiers, IEEE J. Quant. Electron. 34(12), 2393-2402 (1998).

[25]D.C. Brown, Ultrahigh-average-power diode-pumped Nd:YAG and Yb:YAG lasers, IEEE J. Quant. Electron. 33(5), 861-873 (1997).

[26] B.A. Reznikov, Yu.I. Sirotin, and N.E. Voropaeva, Determination of the temperature dependence of the piezo-optical and elasto-optical coefficients of crystals, Phys. Status Solidi 33(2), 633-640 (1969).
[27]R.W. Dixon, Photoelastic properties of selected materials and their relevance for applications to acoustic light modulators and scanners, J. Appl. Phys. 38(13), 5149-5153 (1967).

[28] A.S. Dement'ev, A. Jovaiša, E. Stupak, and R. Kačianauskas, Thermal stresses and end-bulging in cylindrical laser rods under longitudinal diode laser pumping, J. Therm. Stresses 37(1), 73-92 (2014).

[29]E. Leibush, S. Jackel, S. Goldring, I. Moshe, Y. Tzuk, and A. Meir, in: Advanced Solid State Photonics 2005, OSA Trends in Optics and Photonics Series (Optical Society of America, 2005).

[30]S. Radmard, A. Haghparast, S. Arabgari, and M.T. Mehrabani, High-power Yb:YAG/YAG microchip laser using octagonal-shape waveguide with uniform absorbed power distribution, Opt. Laser Technol. 48(1), 44-51 (2013).

\title{
SĄLYGOS MAŽINTI ŠILUMINES SFERINES ABERACIJAS IŠ ŠONO KAUPINAMUOSE YAG STRYPUOSE
}

\author{
D. Bričkus, A.S. Dementjev \\ Fiziniu ir technologijos mokslu centras, Vilnius, Lietuva
}

\begin{abstract}
Santrauka
Šiluminio laidumo ir termooptinio koeficiento $\mathrm{d} n$ / $\mathrm{d} T$ temperatūrinès priklausomybès yra vienas pagrindinių veiksnių, lemiančių šiluminių aberacijų atsiradimą, tačiau jos ne visada yra ịskaitomos nagrinejjant šiluminius lęšius kietojo kūno lazeriuose. Šiame darbe rastas šiluminès lygties su temperatūriškai priklausančiu šiluminio laidumo koeficientu bendras integralinès išraiškos pavidalo sprendinys, patogus naudoti tiek analitinei, tiek skaitinei analizei. Pasitelkus ši sprendinị detaliai išnagrinèta galimybè panaikinti šilumines sferines abera-
\end{abstract}

cijas parenkant tam tikros formos parabolini kaupinimo pasiskirstymą.

Aptarti optinio kelio skirtumo apibrèžimų, naudojamų ankstesniuose darbuose, netikslumai, kai termooptinis koeficientas priklauso nuo temperatūros. Parodyta, kad naudojant teisingą apibrèžimą parabolinio koeficiento verté, kai pasiekiamas sferinių aberacijų panaikinimas, padideja, palyginti su gaunama naudojant Hodgsono ir Weberio išraišką. Taip pat rasta, kad tiek radialinès, tiek tangentinès poliarizacijos sferinems aberacijoms panaikinti reikalinga beveik ta pati kaupinimo forma. 